\title{
The network of international trade in services
}

\author{
Lucia Tajoli ${ }^{*}$, Federico Airoldi ${ }^{2}$ and Carlo Piccardi ${ }^{*}$ (1)
}

\author{
${ }^{*}$ Correspondence: \\ lucia.tajoli@polimi.it; carlo. \\ piccardi@polimi.it \\ ${ }^{1}$ Department \\ of Management, Economics \\ and Industrial Engineering, \\ Politecnico di Milano, Milan, \\ Italy \\ ${ }^{2}$ Department \\ of Electronics, Information, \\ and Bioengineering, \\ Politecnico di Milano, Milan, \\ Italy
}

\begin{abstract}
While the share of services in international trade has been increasing very slowly over the years, oscillating around 20 per cent since the 1990s, their role has constantly gained importance. Trade in services certainly faces many more obstacles than trade in goods, but its impact on globalization and countries' competitiveness is crucial, and it is therefore worth investigating its characteristics. The present work aims to analyse the networks of international trade in services and to unveil specific properties by exploiting a number of existing methodologies and algorithms. After describing the global properties of the networks of the various service classes, we investigate differences and similarities among them, and we highlight the most influential countries in the trade of specific services. We find that traded services display sharply different characteristics and they can be grouped in two different sets according to their network structures. Countries' positions in these networks are diversified, with connections unevenly distributed, especially for some service categories. We discover that the structure of links, i.e. the topology of the networks, identifies the role of countries much more clearly than the sole amount of services traded. Overall, the results highlight important features, as well as changes over time, in the landscape of the international services.
\end{abstract}

Keywords: Trade in services networks, Centralization, Network distance, Countries centrality, Countries role

\section{Introduction}

The role of services in international trade has been increasing over time and, according to some observers, in the 21 st Century services will define the ability of countries and their firms to compete on international markets (WTO 2019). This is due to two distinct aspects related to the rise of services. First of all, thanks to improvements in information and communications technology, services have become more and more internationally tradable, as many types of service providers, such as computer programmers, consultants or call-center operators, no longer need to be physically close to their customers, as long as they can rely on digital connections to deliver their services. The second component is just as relevant: not only are more services crossing borders, but domestically produced services are also vital inputs to the production and exchange of increasingly complex traded goods and services. As more production enters the global value chain model, crossing multiple countries in the transition

(c) The Author(s), 2021. Open Access This article is licensed under a Creative Commons Attribution 4.0 International License, which permits use, sharing, adaptation, distribution and reproduction in any medium or format, as long as you give appropriate credit to the original author(s) and the source, provide a link to the Creative Commons licence, and indicate if changes were made. The images or other third party material in this article are included in the article's Creative Commons licence, unless indicated otherwise in a credit line to the material. If material is not included in the article's Creative Commons licence and your intended use is not permitted by statutory regulation or exceeds the permitted use, you will need to obtain permission directly from the copyright holder. To view a copy of this licence, visit http:// creativecommons.org/licenses/by/4.0/. 


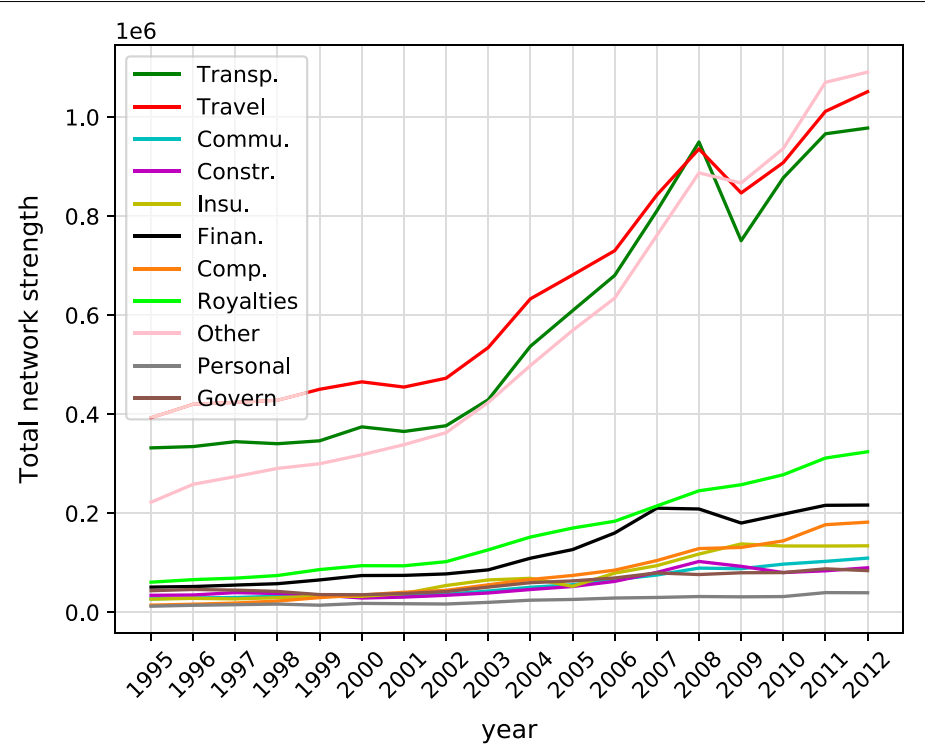

Fig. 1 Total world export (million US dollars) per service category during the analysed period

from raw material to finished good, services necessary to this international organization of production become more widespread, and their efficiency and reliability can determine countries' and firms' outcome. This phenomenon touches countries at all income levels and has important implications for development.

Even if services represent by far the largest share of value added in most countries, and international trade in services has witnessed dynamic growth in recent decades (see Fig. 1), the global value of international trade in goods remains approximately three times as high as that of services. Part of this imbalance may be due to the nature of many services. The term "services" covers an heterogeneous range of intangible products and activities that are difficult to encapsulate within a simple definition. Services are also often difficult to separate from the goods with which they may be associated in varying degrees and are often the result of a production activity that changes the conditions of the consuming units, or facilitates the exchange of products or financial assets (UN, Eurostat, IMF, OECD, WTO 2011). Services are intangible, implying that the international trading of services is inherently subject to more constraints. While a tangible good may be produced, stored, moved and consumed at different places and times, the consumption of some services still requires the close physical proximity of service provider and consumer/customer, as not all services can be delivered digitally. Services are often more tightly regulated than goods: for example, some professional services, such as accountancy, may be bound by distinct national legislations, which has the potential to restrict the supply of services across countries' borders. Finally, some services are largely supplied by the public sector (for example, within services such as health or education), creating additional constraints to their tradability. Therefore, services differ from goods in a number of ways, and so do their trade patterns.

Since the introduction of trade in services within the framework of the World Trade Organization (WTO), the economic literature analysing the patterns and the 
characteristics of this type of trade has been growing. Some recent works compared trade in services to the more familiar trade in goods (Kimura and Lee 2006; Miroudot et al. 2013), while others stressed its importance in today's global markets (Francois and Hoekman 2010). For example, Freund and Weinhold (2002) unveiled how the development of Internet has been facilitating the USA export of services in recent years, both directly and indirectly. Such analysis, however, are limited to information provided by single countries or small groups of them and lack an overall vision of how trade in services behaves globally. ${ }^{1}$

An effort to develop a comprehensive database on trade in services has been put forward by OECD and WTO, resulting in the Balanced Trade in Services Dataset (BaTis) (OECD-WTO 2017; Fortanier et al. 2017), the first dataset describing trade in services in an international context at the bilateral level. The present work uses the first release of these data to perform a complex network analysis. This approach allows to study the overall structure of services exchange between countries and to compare it to the structure of other international trade networks, like the trade in goods which has been already analysed in the past. It is quite natural to represent international transactions among countries as a network, where countries are the nodes and the connecting edges are the trade flows between them, giving rise to an intricate system of exchanges affecting all countries. As services are an increasingly important part of the international economy, understanding how countries integrate their service markets and the resulting international market structure is meaningful.

While considering international trade under a complex network theory approach, many aspects are worth to be investigated, including: similarities between networks related to different services classes, which are the most influential countries in the trade of specific services, where their trade mostly takes place, and if there are groups of nations that share similar commercial connections in some services categories. Some of these aspects have been studied in previous works by considering international trade in goods (De Lombaerde et al. 2018), and more rarely some specific services. For example, Schiavo et al. (2010) showed that the international trade and financial networks are both characterized by a core-periphery structure where the high income countries form a tightly connected core of nodes while the low income ones act as peripheral nodes, thus they are sparsely connected both to each other and to the core ones, and suggested that such a kind of topological structure can explain why the recent financial crises spread rapidly in advanced nations and reached emerging economies only in a second phase. Also the relationships between traded product characteristics and corresponding trade networks topologies have been investigated by Piccardi and Tajoli (2018) and Cingolani et al. (2018). Both analyses, even if focused on different types of product features (the

\footnotetext{
${ }^{1}$ The relative scarcity of empirical analysis of trade in services, especially considering their global and bilateral patterns, is probably mainly due to the unavailability until recently of a detailed database of international trade of services. A reason for the lack of reliable global data on trade in services is the difficulty in measuring the phenomenon, as services can be traded following different modes. The General Agreement on Trade in Services (GATS) (WTO 1995), a WTO's treaty aimed to provide international rules ensuring an equitable and fair treatment of all participant nations, defines four different modes of supply that are currently used to deliver services: Cross-border supply (the service is supplied without movement of the consumer nor of the supplier, for instance via a phone call or by e-mail, e.g. many financial services); Consumption abroad (the consumer moves into another territory to consume the service, e.g. tourism); Commercia presence (the service supplier establishes a local presence, for instance by opening subsidiaries, e.g. transport or retailing); Presence of natural persons (the supplier moves to the consumer location to provide the service, e.g. consultancy).
} 
degree of complexity rather than the intermediate or final sort of the goods), demonstrate that the international trade networks topology differs systematically across different types of goods. The existence of a relationship between the characteristics of the object traded and the structure of the networks hints to the possibility of finding specific structures for traded services. Analyzing the gobal structure of trade in services is also important to understand how this sector reacts to global shocks, as done in Serrano et al. (2007) for trade in goods, where the authors defined a procedure to analyse this type of phenomenon and studied the crises propagation processes in international trade networks. Trade in services has shown to be very resilient to financial and economic shocks in the past (Borchert and Mattoo 2010), but the current economic crisis caused by the Covid pandemic has registered a drop in trade of some types of services much deeper than for goods. Network analysis of the global service exchanges can help to deduce when we observe fragility rather than resilience.

The present work aims to analyse some of the just mentioned aspects by exploiting existing methodologies and algorithms to unveil specific properties of the networks. In Dataset description section we present the characteristics of the dataset we use. In Global network properties section trade in services networks are characterized in function of some global topological properties, including network density and centralization, and we discuss how these properties evolve over time and change across different types of services. Comparing services networks section shows the results of the network comparison of the dataset after their reduction to unweighted directed version. Interestingly, we find that there two distinct classes of services, displaying different network structures and different evolution over time. The last part of the paper considers countries' position in these networks. Countries' centralities section deals with the task of finding important/influential countries in international trade by analysing a set of centrality measures computed on the graphs' nodes, and Classifying nodes' roles section continues this analysis by focusing on the topological properties of the nodes. The trade of many services is strongly concentrated within a small group of countries playing a key role in the overall network structure, displaying some potential fragilities. Also, the position of some countries changed remarkably over time, confirming the evolution of the international service markets. Sect. Concluding remarks draws some conclusions from the presented evidence.

\section{Dataset description}

As mentioned in the previous section, the measurement of services trade is a challenging and demanding task since they can be delivered via a variety of methods, and being intangible, unlike goods, they can cross national borders without being detected. Additionally, despite the existence of international methodological guidelines, countries use a variety of sources and estimation techniques to develop their own services trades estimates and the further presence of confidential data makes it more difficult to achieve the goal of a truthful collection of such data. For these reasons, the creation of a bilaterally coherent dataset of services trade at the global level requires a specific methodology. This has been developed by OECD and WTO: such procedure leverages the available data and combines them with estimates obtained via different methods including interpolation and regression models. 
More in detail, the BaTis database released in 2017 is the result of the application of a multi-fold methodology that relies on all official data sources to exploit all the available data, applying different procedures according to the amount of information available. For a number of countries, interpolation and estimates were necessary to fill the missing data on service trade by category and by partner. The estimates were derived from an econometric gravity model carefully specified, using the Poisson Pseudo-Maximum Likelihood estimator (PPML). In this context, the PPML estimator is appropriate (see e.g. Silva and Tenreyro 2006), as it avoids biases in the parameter estimates in the presence of heteroscedasticity, does not require a Poisson distribution and especially it allows for the presence of zero trade flows, allowing the underlying binary structure to emerge (Dueñas and Fagiolo 2013). The estimate results appear highly reliable, and their consistency with all the available reported figures is carefully assessed, with special care in treating some extreme cases of peculiar countries. The BaTis dataset aims to provide high quality and transparently developed detailed trade in services statistics for the purposes of constructing global reliable indicators (Fortanier et al. 2017). For these reasons, we trust its reliability in performing a network analysis of trade in services.

The OECD-WTO BaTis dataset (OECD-WTO 2017; Fortanier et al. 2017) we use here provides data for the 1995-2012 period covering 191 countries and disaggregating for the 11 main Extended Balance of Payments Services (EBOPS) classification categories listed in Table 1. We analyze the dataset with a network analysis point of view: BaTis is used to define, for each year $y$, twelve different network layers $G_{y s}, 11$ corresponding to the EBOPS services classes $s$, plus one aggregated level:

$$
G_{y s}=\left(V, E^{(y s)}\right), \quad y \in\{1995, \ldots, 2012\}, \quad s \in\{\mathrm{S} 200, \mathrm{~S} 205, \ldots\} .
$$

The graphs are directed and weighted, and defined on the set $V$ composed by $n=191$ nodes, each representing a country. The edge $e_{i j}^{(y s)} \in E^{(y s)}$ denotes an export activity of service type $s$ during year $y$ from country $i$ to country $j$, and its weight $w_{i j}^{(y s)}$ is the estimated value (in million US dollars) reported in the dataset. Overall, there are therefore $18 \times 12=216$ networks describing the trade in services flows during the aforementioned period.

Figure 1 reports the total world export per service category during the analysed period. We see that Transportation (S205), Travel (S236) and Other business services (S268) display the highest values over the whole period, and this is increasing at a fast pace. Also other service categories, even if smaller in value terms, have been increasing rapidly. The general rising trend is interrupted, for some categories, by a sudden drop in 2009-a well known effect of the Great Recession, the financial crisis that started in 2007-2008. But we can also see that other service categories display a remarkable stability over time, as mentioned by Borchert and Mattoo (2010), or even a continuously increasing trend, apparently unaffected by the Great Recession.

\section{Global network properties}

For all years and service categories, graphs show a high level of connectivity with a single Weakly Connected Component (WCC), actually including the whole node set, and a single Strongly Connected Component (SCC) which is smaller than the WCC of at most 


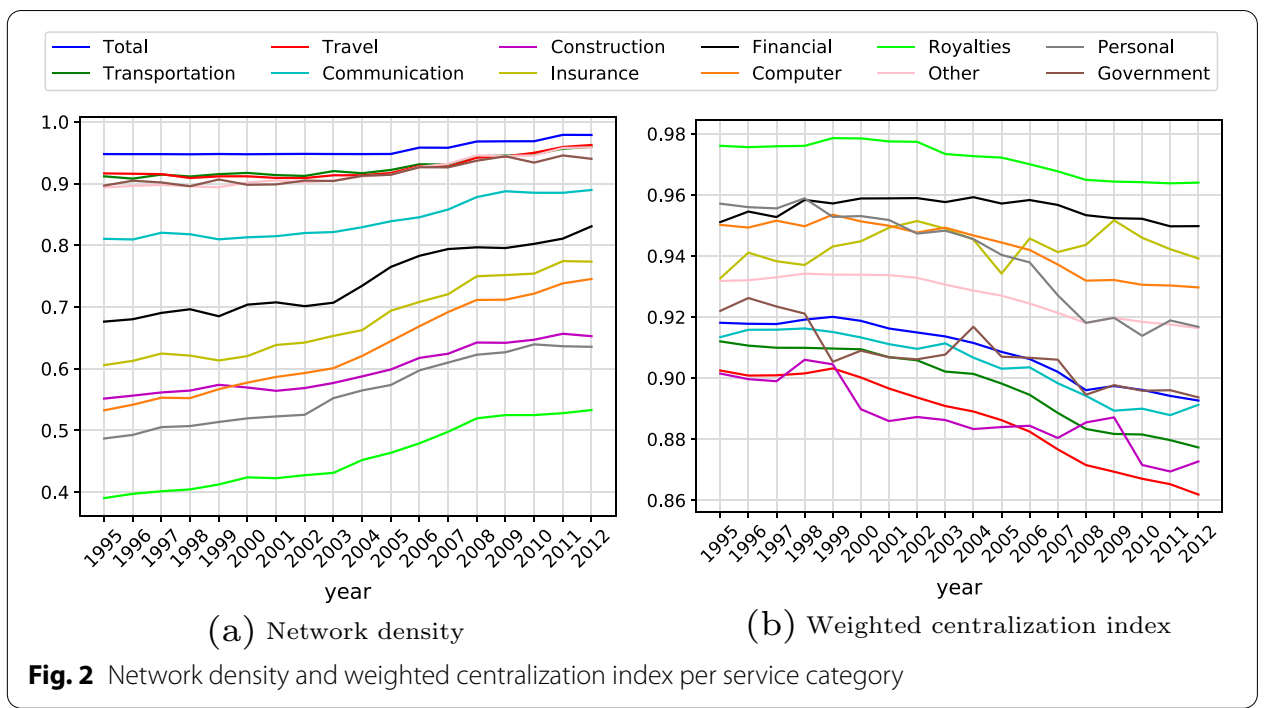

a few nodes. This is the effect of a network density which is large in general (Fig. 2a), extremely large for a few categories, and even increasing over time as long as new relationships are established.

We group together Transportation (S205, i.e. carriage of people and objects from one location to another as well as related supporting and auxiliary services and rentals), Travel (S236, i.e. tourism, encompassing a range of goods and services consumed by non-residents in the economy that they visit, most commonly accommodation, food, beverages and transport), Government services (S291, i.e. goods and services supplied by and to enclaves, such as embassies and military bases), Other business services (S268, which includes research and development services, professional and management consulting services and technical, trade-related and other business services), and Communication (S245, i.e. broadcast or transmission of sound, images, data, or other information through electronic means, including also business network services, teleconferencing and support services, mobile telecommunications services, Internet backbone services and online access services, including the provision of access to the Internet), to form the group we name Connection services. In fact, these are services whose primary purpose is to keep connected locations which are geographically dispersed, by moving around goods and people, and linking firms's subsidiaries and government legations around the world to their main offices. From Fig. 2a we note that these are the categories with the highest network density, close to 0.9 or higher at the end of the period, a manifest representation of globalization, as through these specific types of services the large majority of countries appear connected to nearly every other country in the world.

The remaining service networks include Construction (S249, i.e. creation, management, renovation, repair or extension of fixed assets in the form of buildings, land improvements of an engineering nature and other constructions), Insurance (S253, i.e. provision to non-residents of various types of insurance by resident insurance enterprises, and vice versa), Financial services (S260, i.e. financial intermediation and auxiliary services, usually provided by banks and other financial intermediaries except those of insurance enterprises and pension schemes, encompassing, inter alia, deposit taking 
and lending, letters of credit, credit card services), Royalties (S266, i.e. charges for the use of intellectual property, including charges for the use of proprietary rights, such as patents, trademarks, copyrights, industrial processes and designs, charges for licenses to distribute intellectual property, such as copyrights on books and manuscripts, computer software, cinematographic works and sound recordings, production of books, recordings, films, software, disks), and Computer and information services (S262, i.e. hardware- and software-related services, customized or mass-produced, and data processing services). These five categories are often known as Business-based services as these are services mainly used by firms and corporations. The last category is Personal services (S287, i.e. audiovisual and related services and other personal, cultural, and recreational services), which have a different nature ${ }^{2}$. This second group is characterized by lower values of density, yet clearly increasing along the 1995 - 2012 period. While Connection services, namely the first group above, have always crossed countries' borders at least to some extent, in the past this second group was much less globalized and has seen an increase in internationalization mainly thanks to the development of digital technologies allowing exchanges without physical proximity.

The different network structures of Connection services and Other services (in this latter class we aggregate Business-based services and Personal services, as above discussed) is apparent also in the examples reported in Fig. 3, where we show the networks of Transportation services (S205) and Financial services (S260) in 2012. The figure highlights the typical features of the analysed graphs, namely the presence of a few big actors and the large number of edges, but also the higher density of Connection services, typically featuring also a larger number of high-strength nodes.

The behaviour of the densities of trade in services networks over time (Fig. 2a) is similar to that of the World Trade Network (WTN) of goods in years from 1995 to 2010 (De Benedictis et al. 2014) and indeed in both cases the number of connections is quite high and visibly increases over time. It is however important to note a relevant difference between the two types of trades, since the WTN density shows a significant drop in years 2008 and 2009 that is totally absent in the case of trade in services networks. The big trade collapse seems to have attacked the trade of some services only in terms of total strength, as can be seen in Fig. 1, but not in terms of connections among countries, revealing a sort of topological resiliency to financial and economical shocks. Even financial services, at the core of the Great Recession of 2008-2009, while displaying a short term drop in the traded values, do not record any reduction in the number of links across countries.

Figure $2 \mathrm{~b}$ shows the time pattern of the weighted centralization index for all the service categories: here we use the vulnerability index defined by Piccardi and Tajoli (2018) and based on the work by Dall'Asta et al. (2006) (see "Appendix 1"). It measures how rapidly the aggregated network weight is lost when connectivity decreases because nodes are subsequently removed starting from those with largest export flow. Very centralized networks, i.e. those where the export is concentrated in few countries, are more vulnerable, as most of the flow is destroyed when removing those countries. Generally speaking,

\footnotetext{
${ }^{2}$ For a complete description and examples for each category, see UN Statistics Division (2010).
} 


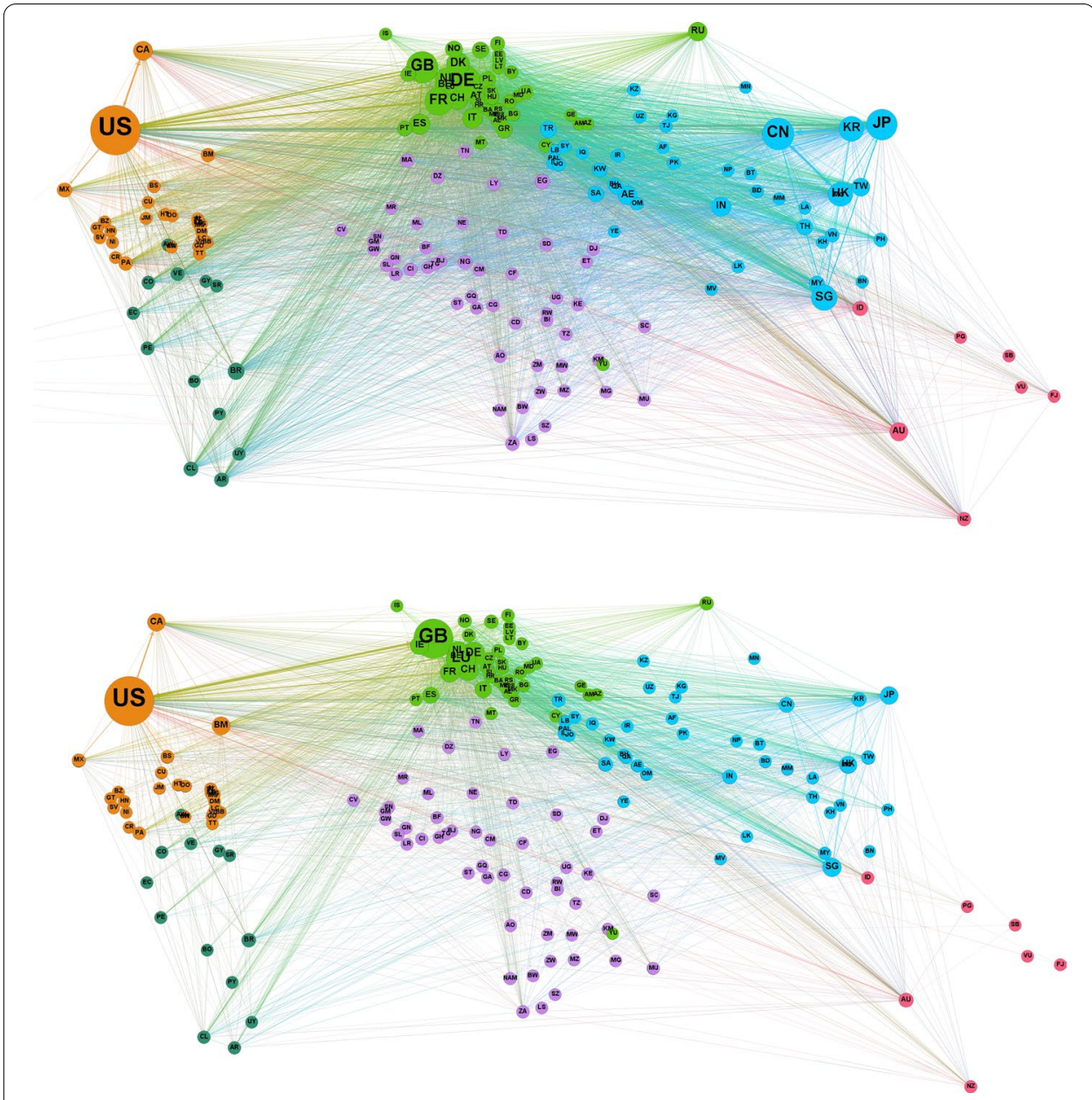

Fig. 3 The networks of Transportation (S205, top) and Financial services (S260, bottom) in year 2012. Node size is proportional to the total strength (i.e. import + export flow), edges thickness to the weight. Only edges with $w_{i j} \geq 1$ (million US dollars) are depicted

Table 1 The 11 EBOPS service categories S205 to S291 as reported by BaTis. The first one, Total services (S200), is the aggregate of all the others

\begin{tabular}{lll}
\hline Code & Name & Description \\
\hline S200 & Total services & \\
S205 & Transportation services & $\begin{array}{l}\text { Sea, air, space, rail, road, inland waterway, transportation and pipe- } \\
\text { line transport (passenger and freight) }\end{array}$ \\
S236 & Travel services & Business and personal travels \\
S245 & Communication services & Postal-courier and telecommunication services \\
S249 & Construction services & Construction abroad and construction in the compiling economy \\
S253 & Insurance services & Pension funding, life, freight and direct insurances, and reinsurance \\
S260 & Financial services & Banking and financial investment services \\
S262 & Computer and information services & $\begin{array}{l}\text { Computer, information, news agency and other information provi- } \\
\text { sion }\end{array}$ \\
S266 & Royalties and license fees services & Franchise and royalties fees \\
S268 & Other business services & Merchanting and trade-related, operational leasing \\
S287 & Personal services & Audiovisual, education, health and others \\
S291 & Government services & Embassies and military units \\
\hline
\end{tabular}




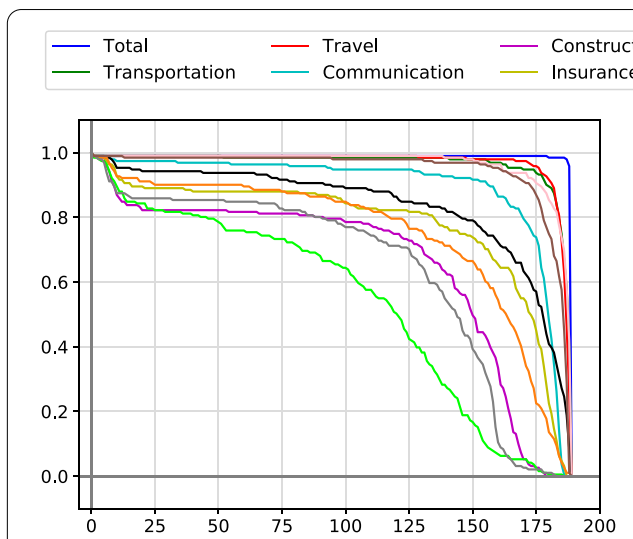

(a) Out-degree CDFs

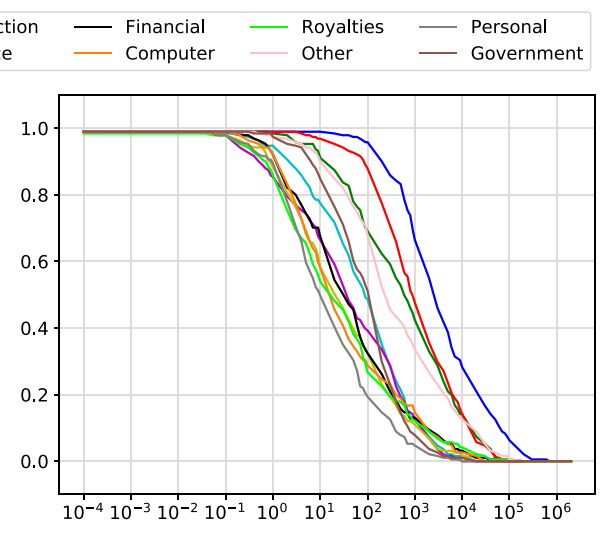

(b) Out-strength CDFs

Fig. 4 Out-degree and out-strength CDFs per service category in year 2012

after a suitable normalization, index values tending to 1 denote star-like graphs, whereas values close to 0 reveal distributions of edges and weights that tend to be homogeneous among all nodes. If we ignore edge weights (i.e. set them all to 1), namely we focus on the pure network topology, centralization turns out to be small for all categories (not reported for brevity ${ }^{3}$ ) - an effect of the large density. If we however account for weights, as in Fig. 2b, we find large values for all categories. Notice that, in the weighted version of the index, large values can also be achieved by very dense networks, if the total export is handled by a limited number of countries. It is worth noting that Financial services (S260) rank second in terms of centralization. This characteristic, together with the high density, can explain the widespread and fast propagation at the world level of the shock that hit the US financial sector back in 2008.

Combining density and centralization, we understand that the international trade in services is spread around the globe, but most of the commercial flow derives from a restricted number of nations. Interestingly, for the whole of services this compression of the network strength around few nodes is slowly decreasing over time (blue line of Total services (S200) in Fig. 2b), and the reduction in centralization is even clearer for some categories, such as Travel (S236), Communication (S245), and Transportation (S205)-a reduction related to some Connection services that confirms the ongoing globalization in the observed period.

The above remarks are corroborated by the patterns of degree and strength distribution of the network nodes. Figure 4 reports two representative ensembles of curves, namely the Cumulative Distribution Functions (CDFs) of out-degree and out-strength in 2012, respectively defined as

$$
P_{k^{\text {out }}}(k)=\frac{\mathrm{n} \text {. of nodes with out-degree } \geq k}{n},
$$

\footnotetext{
${ }^{3}$ The full set of results (for all sections of the paper) is available from the authors on request.
} 


$$
P_{s^{\text {out }}}(s)=\frac{\text { n. of nodes with out-strength } \geq s}{n} .
$$

We recall that the out-degree $k_{i}^{\text {out }}$ of node $i$ is the number of outgoing edges, i.e. the number of export destinations, while the out-strength $s_{i}^{\text {out }}$ is the sum of weights $w_{i j}$ of such edges, i.e. the total export flow. Figure 4a reveals that the out-degree CDFs have quite different patterns depending on the service class type. Connection services are mostly composed by a large majority of high degree nodes, while Business-based services show a more uniform decay of the distribution of degrees-this is particularly evident for Royalties and licence fees (S266), which is also the class with the lowest density (Fig. 2a). Remarkably, Business-based services' out-degree CDFs have peculiar sharp drops in correspondence of small degree values-the same happens for in-degree CDFs (not reported for brevity). This reveals the existence of a sizeable group of countries which export services only to a small number of importers and/or import only from a limited group of exporters, an effect which is not observed in the WTN of goods. This pattern might be due to the higher barriers that service trade faces with respect to trade in goods, imposing a stricter selection of partners. As far as the out-strength CDFs are concerned (Fig. 4b), we note that all categories exhibit the same qualitative behaviour: the curves confirm the already mentioned fact that most of the network flow concentrates around very few nodes, supporting the high values of the weighted vulnerability indices (Fig. 2b).

\section{Comparing services networks}

Are different services traded similarly? Have the topologies of their trade networks any common trait? Have they modified over the years? Some preliminary observations on the topology of the networks suggest that there are some common traits as well as relevant differences among services' categories. We try to answer these questions more precisely by using the tools of network comparison (Tantardini et al. 2019): among the many available metrics, we employ Directed Graphlet Correlation Distance (DGCD) (Sarajlic et al. 2016), which is able to quantify the distance between two directed, unweighted networks by comparing the distributions of suitable small directed subgraphs ("graphlets"). For that, we need to reduce our networks from weighted to unweighted-a non trivial process, requiring a systematic method to define whether a link is important or can be discarded.

We rely on the notion of Revealed Comparative Advantage (RCA) (Balassa 1965), an economic index that quantifies the export and import advantages of countries involved in the trade of a given set $P$ of products. Given a multi-product network describing commercial relationships for such set $P$, the RCA provides a set of $2|P|$ indices to each country $c$ : they quantify the relative relevance of the different products for the country's export $\left(R C A_{c p}^{e x p}\right)$ and import $\left(R C A_{c p}^{i m p}\right)$ activities:

$$
R C A_{c p}^{e x p}=\frac{e_{c p} / \sum_{p^{\prime} \in P} e_{c p^{\prime}}}{\sum_{c^{\prime} \in C} e_{c^{\prime} p} / \sum_{c^{\prime} \in C} \sum_{p^{\prime} \in P} e_{c^{\prime} p^{\prime}}}, \quad R C A_{c p}^{i m p}=\frac{i_{c p} / \sum_{p^{\prime} \in P} i_{c p^{\prime}}}{\sum_{c^{\prime} \in C} i_{c^{\prime} p} / \sum_{c^{\prime} \in C} \sum_{p^{\prime} \in P} i_{c^{\prime} p^{\prime}}},
$$



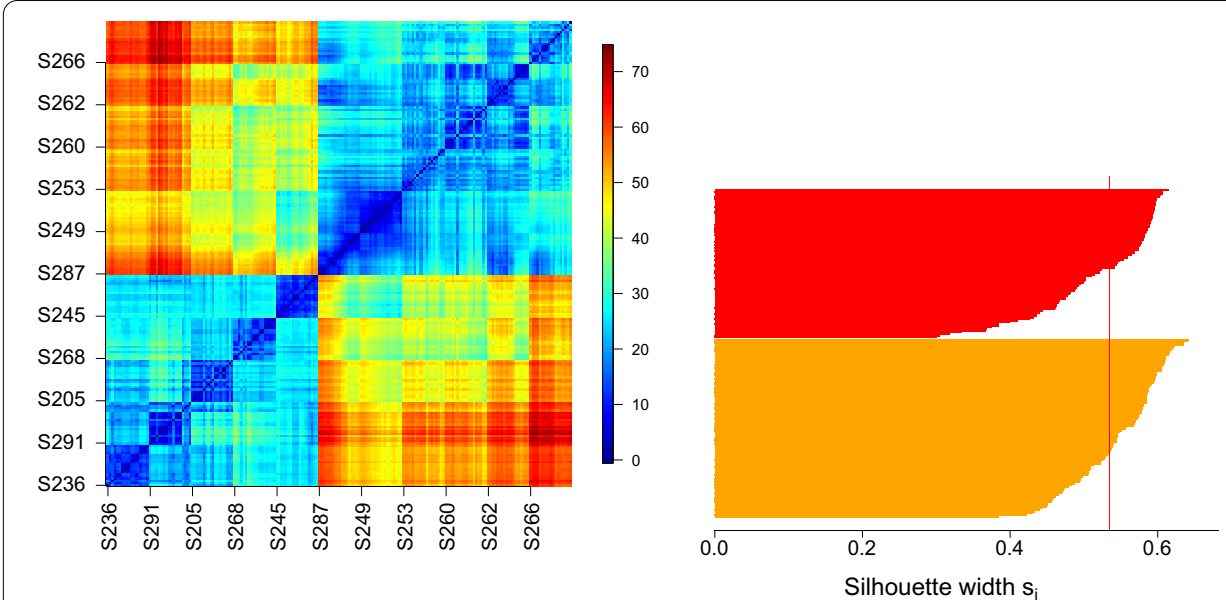

Fig. 5 Left: Heatmap of DGCD-129 distance matrix for the reduced networks. Rows and columns are primarily ordered by service class, and then by year from 1995 to 2012. The colorbar shows that the colder the colour, the smaller the distance between graphs, i.e. the higher their similarity. Right: Silhouette plot for the two-group clustering dictated by the heatmap. The vertical red line denotes the average silhouette value (0.53)

where $e_{c p}$ and $i_{c p}$ denote, respectively, the total export and total import of product $p$ by country $c$. We say that a country $c$ has comparative advantage in export (resp. import) in the trade of product $p$ if $R C A_{c p}^{\exp } \geq 1$ (resp. $R C A_{c p}^{i m p} \geq 1$ ). Then we preserve outgoing links of nations showing comparative advantage in export, and incoming links of those showing comparative advantage in import. We underline that the use of RCA does not prevent any node to be part of the resulting directed unweighted networks just because it has low export or import in absolute terms, because RCA values, being comparative indicators, are not only based on the flow proportion that a country brings to the total trade of a certain product, but also on its total export/import in all products. Additionally, even if a country does not show a comparative advantage in a given service category in neither import or export, it is not foreclosed to be part of the reduced graph since it may import from relevant exporters or export to relevant importers. Applying the procedure, we obtain $11 \times 18=198$ reduced graphs, i.e. one for each sector (excluding the aggregated sector S200, instrumental for defining the RCA indices of the other sectors, but for which the index cannot be defined, see Eq. (4)) and year. The resulting graphs contain the same nodes of the original networks and have, by construction, lower density than the original counterparts.

The heatmap summarizing the DGCD-129 distances (Sarajlic et al. 2016) among the reduced graphs is displayed in Fig. 5 (left panel). A clear clustering in two groups of service classes emerges: the first group is formed by Transportation (S205), Government (S291), Travel (S236), Communication (S245), and Other business (S268) services (bottom-left corner of the heatmap); the second one by the remaining categories, namely Personal (S287), Construction (S249), Insurance (S253), Financial (S260), Computer (S262), and Royalties (S266) services (top-right corner). Remarkably, this separation corresponds to the two groups we identified in Sect. Global network properties, namely Connection services and Other services. 
The significance of the dichotomy visually emerging from the heatmap needs to be validated. Figure 5 (right panel) shows the silhouette plot (Rousseeuw 1987) associated to the two-way partition. In the plot, the silhouette value $s_{i}$ of each graph $i$ is displayed with a horizontal bar, and bars are grouped according to clusters and, in each group, organized in decreasing order. The silhouette value $s_{i}$ is defined as

$$
s_{i}=\frac{b_{i}-a_{i}}{\max \left(a_{i}, b_{i}\right)},
$$

where $a_{i}$ is the average distance between $i$ and the other graphs of the same cluster, and $b_{i}$ is the minimum (over clusters) of the average distances between $i$ and the graphs in a different cluster. Thus $s_{i} \in[-1,1]$, with a large positive value denoting that $i$ is wellmatched to its own cluster. Typically, a large average silhouette value over a cluster reveals its significance, and a large average value over all objects $i$ denotes a meaningful partition. In our case, the cluster averages are 0.52 and 0.55 , respectively, and 0.53 for the entire pool. These values, all above the threshold value of 0.5 typically used, are sufficiently large to denote a fair significance of the partition.

Looking carefully at the diagonal blocks, we note that the graphs of a few service classes turn out to be more compact than others in terms of mutual distances over the years (i.e. the diagonal block appears uniformly dark): for example, S249, S245 and S236 graphs form single groups of mutually close observations, meaning that the corresponding graphs have remained rather stable over the years. Conversely, other classes are characterized by various patterns denoting variation of the graph structure over time: this is the case, for instance, of S262, S260 and S253.

From the heatmap of Fig. 5 it is also possible to note that S268 (Other business) and S245 (Communication) services' graphs are not only characterized by very small distances to other Connection services, but also by rather small dissimilarity scores with respect to some of the Business-based services graphs, as testified by the blue stripes within the off-diagonal (with yellow/red dominance) blocks. Such patterns are likely due to the characteristics of the commercial performances these classes deal with. S268 services include indeed a wide spectrum of commercial serviceoriented performances and so the heterogeneity of included activities may affect its positioning with respect to other classes. S245 services, on the other hand, deal with postal-courier and telecommunication services and are characterized by wide differences in how they are supplied and the types of consumers that exploit them.

DGCD is a so-called "unknown node-correspondence" metrics (Tantardini et al. 2019), i.e. it reflects the differences in the global structure of the networks rather than the local similarities around corresponding nodes. In the case of trade in services networks, this entails that if two graphs are close each other in terms of DGCD, then they necessarily share a similar global structure, but the common connectivity patterns may be centered around different countries. The consequence is that, even if two graphs are similar, the role of a given node (i.e. country) may be different: in Sect. 6 we will further explore the information provided by the DGCD machinery to classify nodes' roles. 


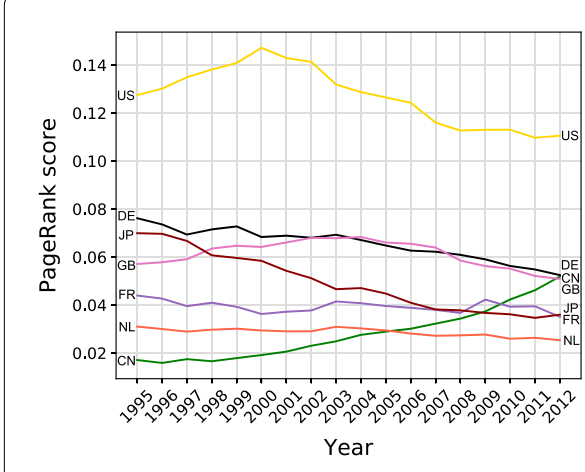

(a) Pagerank for Total services (S200)

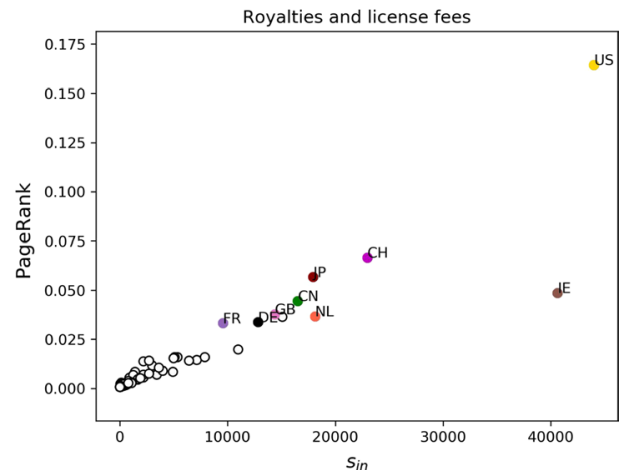

(b) Pagerank vs import value, 2012

Fig. 6 Left: Pagerank time evolution for Total services (S200) (top ranking countries only). Right: Pagerank vs import value for Royalties and license fees (S266) in 2012

\section{Countries' centralities}

After considering some of the global properties of the service networks, we examine the position of individual countries. A first measure of a country's importance is obviously provided by the amount of imported and exported services. In this way, however, the global positioning and influence of the country in the trade network might be disregarded in some cases. More appropriate indicators are needed to quantify to what extent countries are influential in the global trade scenario. For this reason, we compute a set of centrality measures aiming to assess the importance of countries by quantifying network effects (for this analysis, we return to the original directed, weighted network defined in Sect. Dataset description, i.e., RCA reduction is not applied).

Among such indicators we first consider Pagerank (Brin and Page 1998), a broadly used centrality index which is suitable to be applied to directed, weighted networks such as those we are considering. As it is well known, the Pagerank is the proportion of time spent by a random walker on a given node in the long run-a quantity depending on the whole network structure. Figure 6a shows the Pagerank time patterns for the Total services (S200) network (top ranking countries only, for readability). The ranking is largely dominated by US during all the time period under scrutiny: the same happens for all individual service categories (not reported for brevity) with the exception of Construction (S249), where Germany is the leading country (although with decreasing lead over the years). Besides US, other important economies collocate in the top positions, as expected, with a constant rise of China which becomes the third country according to Pagerank at the end of the period of data availability. The rising centrality of China in the service networks highlights the crucial role that services play also in trade of goods. In the observed period, China grew to become the first world exporter of goods, a development unachievable without an intensive use of services.

A well-known property of Pagerank is the high correlation with in-strength (in our case we found Pearson correlation values from 0.913 to 0.999 , for all sectors and years), i.e. import flow. However, anomalies exist and reveal the intricate role of the network ties. For example, let us compare Pagerank and in-strength values for Royalties and license fees (S266). At the beginning of the observation period, Ireland rankings in terms of import flows and Pagerank appear aligned (not reported for brevity) but, since 2003, 


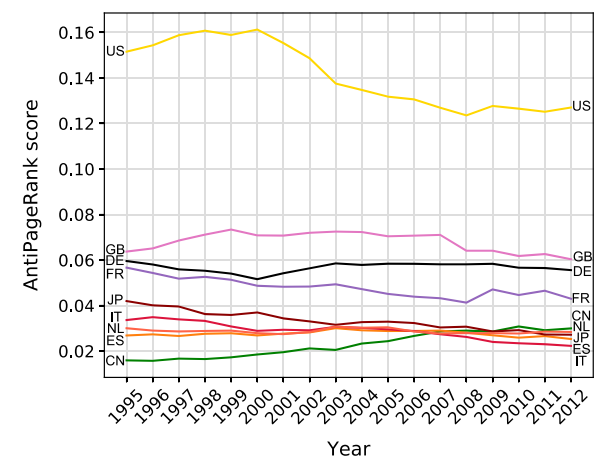

(a) Anti-Pagerank for Total services (S200)

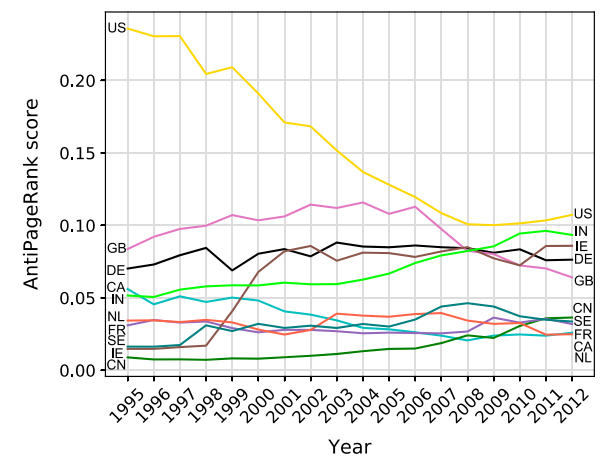

(b) Anti-Pagerank for Computer and information (S262)

Fig. 7 Left: Anti-Pagerank time evolution for Total services (S200) (top ranking countries only). Right: Anti-Pagerank time evolution for Computer and information (S262) (top ranking countries only)

we observe a marked increase in Irish imports of these services following the entry into the country of some high-tech companies. By the end of the observation period (Fig. 6b shows countries' position in 2012) Ireland reaches import levels very close to that of US, yet its Pagerank does not change significantly and it is way smaller (about one third of US), even below other countries with much lower import. This entails that the centrality of US in this sector has to be explained not only by the large import flow, but also by the countries it imports services from-an evident network effect, while the high amount of Irish imports do not make per se the country central. Another sector presenting similar cases of differences in countries' ranking in terms of centrality or in terms of market shares is that of Financial services (S260).

To characterize the export features of countries, rather than import as above, we introduce a dual centrality indicator that we denote Anti-Pagerank, which is simply obtained by computing the Pagerank on the graphs after reverting the link directions. In this "flipped" perspective, the generic link $e_{i j}$ along with its weight $w_{i j}$ represents the income of node $j$ from providing services to node $i$, and the Pagerank (thus Anti-Pagerank for the original graph) will be more correlated to the export side. Indeed, we find Pearson correlation 0.940 to 0.999 between Anti-Pagerank and out-strength, for all sectors and years.

Figure 7a shows the Anti-Pagerank time patterns for the Total services (S200) network (top ranking countries only). Again US are largely dominating, with a small decline just after 2000 followed by stabilization at a lower value. At the sector level, it turns out that on the export side the dominance of US has more exceptions than on the import side (full results not reported for brevity). Construction (S249) is again dominated by Germany, whereas in Insurance (S253) and Financial services (S260) US competes with, among others, UK and Bermuda-the latter being a tax haven where many companies locate their registered offices. In many sectors the dominance of US has slowly decayed over the years: Computer and information services (S262) is an example (Fig. 7b), with US losing centrality without being replaced by any other strong actor reaching a similar star-like position. But in this sector a clearly emerging country is India, which from the year 2000 onward keeps improving its position both in terms of export flows and 
in terms of centrality. It is worth noting again the sharp raise of Ireland in the early 2000s with the establishment in that country of digital giants such as Google. We finally notice that, at least until 2012, the role of China remains minor: for Total Services (S200), exports (captured by the Anti-Pagerank) are not even characterized by the clear growing trend shown on import (Pagerank, Fig. 6a) - a sharp contrast with the scenario observed in the world trade of goods. Some increase in centrality as a service exporter for China is observable for Construction services (S249) and for Transportation services (S205), but not in line with its market share, that grew much more than its centrality.

The previously discussed Pagerank and Anti-Pagerank indicators can be complemented by other centrality measures. Authority/hub scores (Kleinberg 1999) are specifically designed to weigh the node importance according to its connections: highly authoritative nodes are those with heavy in-links coming from nodes with high hub scores, and nodes with high hub scores are those with heavy out-links directed to highly authoritative nodes. Similarly to (Anti-)PageRank, authority/hub are often correlated with in-/out-strength, respectively: that is why, rather than focusing on the ranks that they provide, it is usually valuable to spot nodes that have unexpectedly high or small authority/hub scores if compared with their in-/out-strengths.

Figure 8 shows a few examples of such anomalous behaviours, among the many ones revealed by data analysis. For the network of Total services (S200), in 1995 Japan is the most central nation in terms of authority, despite US and Germany have higher import flows (Fig. 8a). In particular, US shows a relatively small authority score (it ranks fourth), a situation probably caused by the unbalanced distribution of hub scores where US has an enormous lead with respect to all other countries. The situation for Total services (S200) tends to regularize over the years (not in figure), with authority and in-strength becoming more and more aligned, although a few countries, such as Canada, keep anomalously large authority - a fact attributable, in the specific case, to the dominant role of US as a commercial partner. The dual case, i.e. the existence of nodes with really high authority score influencing hub scores, can be noted, e.g. in Government services (S291) in 2012 (Fig. 8b), where the dominant authoritative score of US is likely to have a great effect in the high hub scores of Germany, Korea, and Japan. In 2012, in Transportation services (S205) China shows a high authority (Fig. 8c), possibly related to its need to use imported services from the largest countries for its rapidly growing export flows of goods. On the other hand, the US, somewhat surprisingly given the concentration of high-tech giants in the country and the large amount of export flows in this sector, do not rank at the top as a hub for Computer and information services (S262), probably because they do not target the main markets directly (Fig. 8d). Finally, the presence of financial heavens distorts in unexpected ways the picture of hubs and authorities in Financial services (S260) (Fig. 8e).

\section{Classifying nodes' roles}

In addition to the countries' position in the trade structure, it is possible to highlight other characteristics of countries as service traders. In network analysis, classifying nodes' roles means identifying sets of nodes with structural similarities, for example having analogous topological properties in terms of the structure of their neighbourhood-e.g. centres of star graphs and clique members may represents two different 


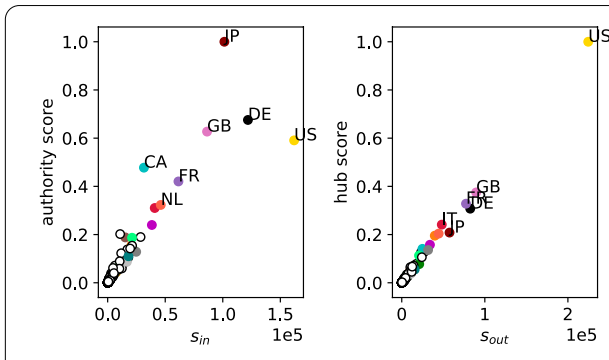

(a) Total services (S200), 1995
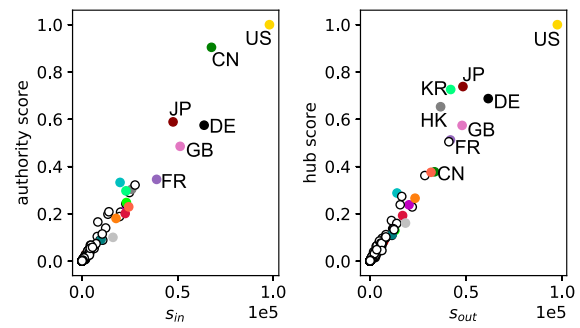

(c) Transportation services (S205), 2012

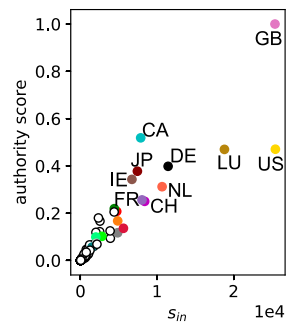

(e) Financial services (S260), 2012

Fig. 8 Comparing authority/hub scores with in-/out-strengths: a few examples
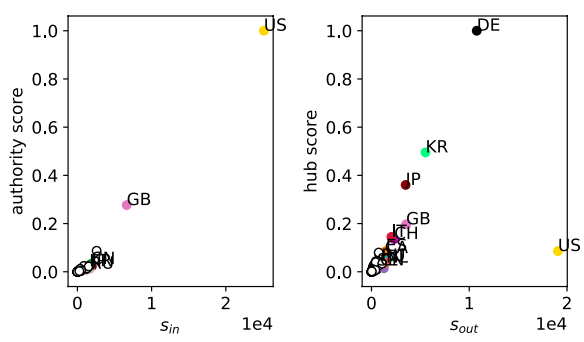

(b) Government (S291), 2012
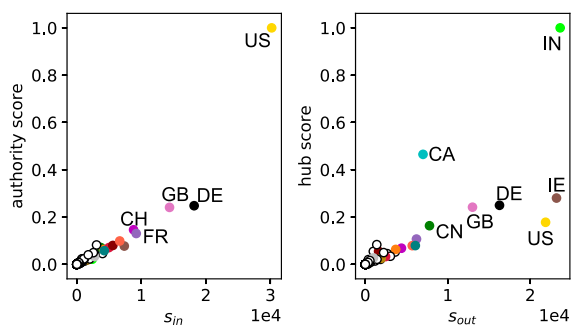

(d) Computer and information services (S262), 2012

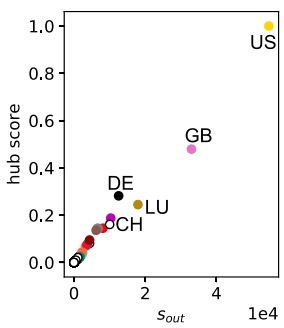

types of roles. The rationale is that classifying roles may disclose the different functions that nodes embody in the system.

In general terms, role classification entails that each node is equipped with a set of "features", i.e. a vector containing all quantities that are considered relevant for classification. Then some form of clustering procedure is carried out to identify groups of nodes with similar features. A number of approaches, based on very different assumptions and methodologies, have been proposed over the years (e.g. Guimera and Amaral 2005; Henderson et al. 2012; Beguerisse-Diaz et al. 2014; Grover and Leskovec 2016; Mechiche-Alami et al. 2019, just to mention a few).

Here we analyze the (directed, unweighted) reduced graphs obtained after the RCA assessment described in Comparing services networks section, and we exploit the results of the graphlet analysis. As a matter of fact, the definition of the DGCD-129 distance passes through the computation, for each node, of the Directed Graphlet Degree Vector (DGDV), whose 129 entries count the frequencies of interaction of the node with the 129 distinct orbits defined by the up to 4-node directed graphlets (see Sarajlic et al. 2016 for details). Thus each node is equipped with a 129-entry features' vector describing in detail its topological neighborhood. 


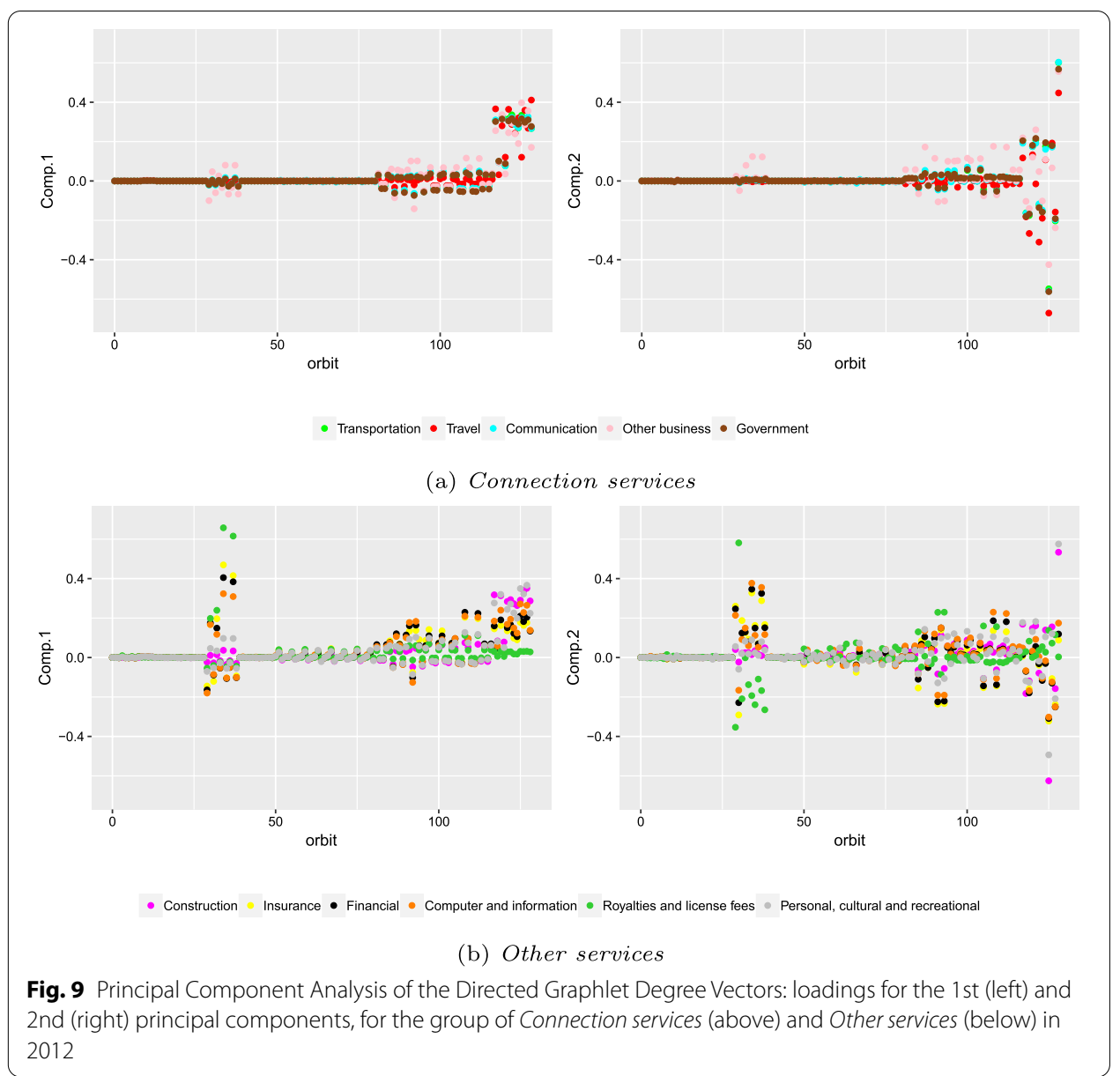

A viable approach to effectively deal with the high-dimensional DGDVs is Principal Component Analysis (PCA), a well-know dimensionality reduction technique for multivariate data (Johnson and Wichern 2008). Analyzing our reduced graphs (11 service classes $\times 3$ representative years, i.e. 1995, 2006, 2012), we find that the proportion of variance explained by the first two principal components is very high and ranges from $83 \%$ to $99 \%$, so that restricting the nodes' information to the 1st and 2nd principal components entails a small loss of information whereas, on the other hand, greatly simplifies the analysis.

The loadings of the 1st and 2nd principal components (i.e. the coefficients of the linear combinations defining the two components as functions of the DGDV entries) are graphically summarized in Fig. 9, separately for the two groups of services classes above introduced, namely Connection services and Other services in year 2012. The 1st component involves, in both groups, a weighted average of orbits from 117 to 129 (see Sarajlic et al. 2016 for the full list of graphlets and orbits), and a contrast between orbits from 81 to 116, where one side encloses the orbits corresponding to degree-3 nodes while the second one embodies the graphlets' nodes with only two links. In Other services this last contrast is heavier in terms of corresponding loadings, denoting a more prominent influence of such orbits in the total variance of 
DGDVs. Additionally, it is possible to note that this component also contains a weighted average of orbits $51,55,59,63,67,71,75$ and 79 , and a contrast between orbits ranging from 29 to 38. The first group of orbits represents, as noted in Sarajlic et al. (2016), nodes involved in brokerage roles in the network, while in the second group the contrast opposes orbits 30,32, 34 and 37, which correspond to center of small star graphlets, and the remaining ones, that correspond to peripheral nodes in such graphlets. The 2 nd principal component of the first group, instead, is constituted by a contrast of orbits from 81 to 128 , mainly distinguishing nodes with more outgoing links from nodes with more in-going links. The second group of service classes presents the same features for the loadings, but additionally is characterized by a contrast involving again orbits from 29 to 38, yet this time the coefficients only oppose orbit 30, the unique sink star-center orbit of star graphlets, to the other ones.

The PCA results directly translate into a tool for classifying countries according to their role. Since the analysis of the DGDVs was restricted to their 1st and 2nd principal component, for any given network the scores of all nodes (i.e. countries) can be visualized on a plane: for example, Fig. 10a refers to the network of Transportation services (S205) in year 2012. Each dot corresponds to a country, with the color distinguishing its RCA features (see Eq. (4)): red for both import and export advantage $\left(R C A_{c p}^{\exp } \geq 1\right.$ and $\left.R C A_{c p}^{i m p} \geq 1\right)$; green for import advantage only $\left(R C A_{c p}^{\exp }<1\right.$ and $\left.R C A_{c p}^{i m p} \geq 1\right)$; blue for export advantage only $\left(R C A_{c p}^{\exp } \geq 1\right.$ and $\left.R C A_{c p}^{i m p}<1\right)$; yellow for no advantage $\left(R C A_{c p}^{\exp }<1\right.$ and $\left.R C A_{c p}^{i m p}<1\right)$. The plot of Fig. 10a shows that four role clusters clearly emerge and, in this specific case, it turns out they coincide with the four categories defined by RCA reduction. It should be stressed, however, that such a role classification-which coincides in this specific case with the RCA categorycannot trivially be recovered from the amount of import/export flows, as shown in Fig. 10b, but it is an emerging property of the topological structure of the network. As a matter of fact, a few of the most central countries (largest in- and out-strength, e.g. US which leads both rankings) have neither import nor export advantage according to RCA classification (yellow dots) while a few of the most peripheral ones (smallest inand out-strength) have both of them (red dots). This means that the graphlet-based role analysis, performed after RCA reduction, classifies countries according to the topological structure of their neighbourhood, in a manner which is largely independent from the absolute import/export values.

By spanning the service classes' networks over the years, the results of the PCA reveal a quite rich and diversified set of scenarios. While in Fig. 10a role clusters match the import/export RCA propensities, in other cases roles emerge in a very different manner: for example, Fig. 11 shows that, for Royalties and licence fees (S266) services, we basically observe only two main role clusters, one collecting a large majority of almost indistinguishable nodes, and the other formed by a small scattered set of countries which clearly depart from such a majority. They are the most active countries in this service class and, interestingly, the composition of this small set has partially modified over the years. This evidence confirms a result shown with other types of analysis, indicating the high concentration in a handful of countries of world R\&D activity, resulting in a small group of countries actively trading the related services. 


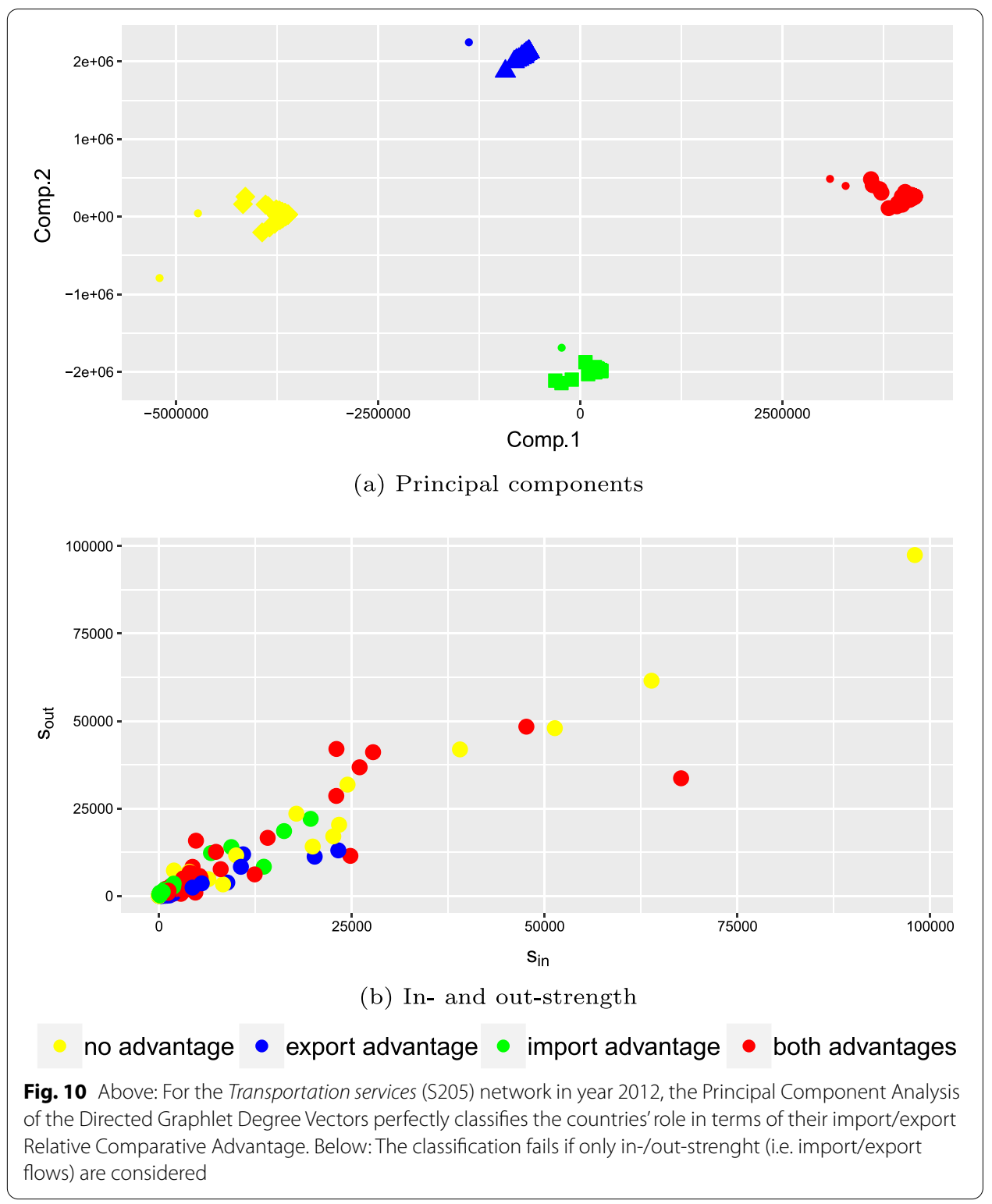

\section{Concluding remarks}

The analysis presented in this work discloses a number of peculiar characteristics of the world network of trade in services. Service trade developed more recently compared to trade in goods, and the value of these transactions, even if rising, is still a fraction of the observed value of trade in goods.

In spite of the smaller weight of the connections, our analysis shows that the network of total service trade displays a high density, even higher than for trade in goods, and a remarkable resilience, confirming the importance of the use of services for all countries and their crucial role for globalization. Considering specific service categories, density is very high especially for the services that we group under the label Connection services (such as Transportation or Travel), that have been internationalized for centuries and reach and connect nearly all countries in the world, but density 


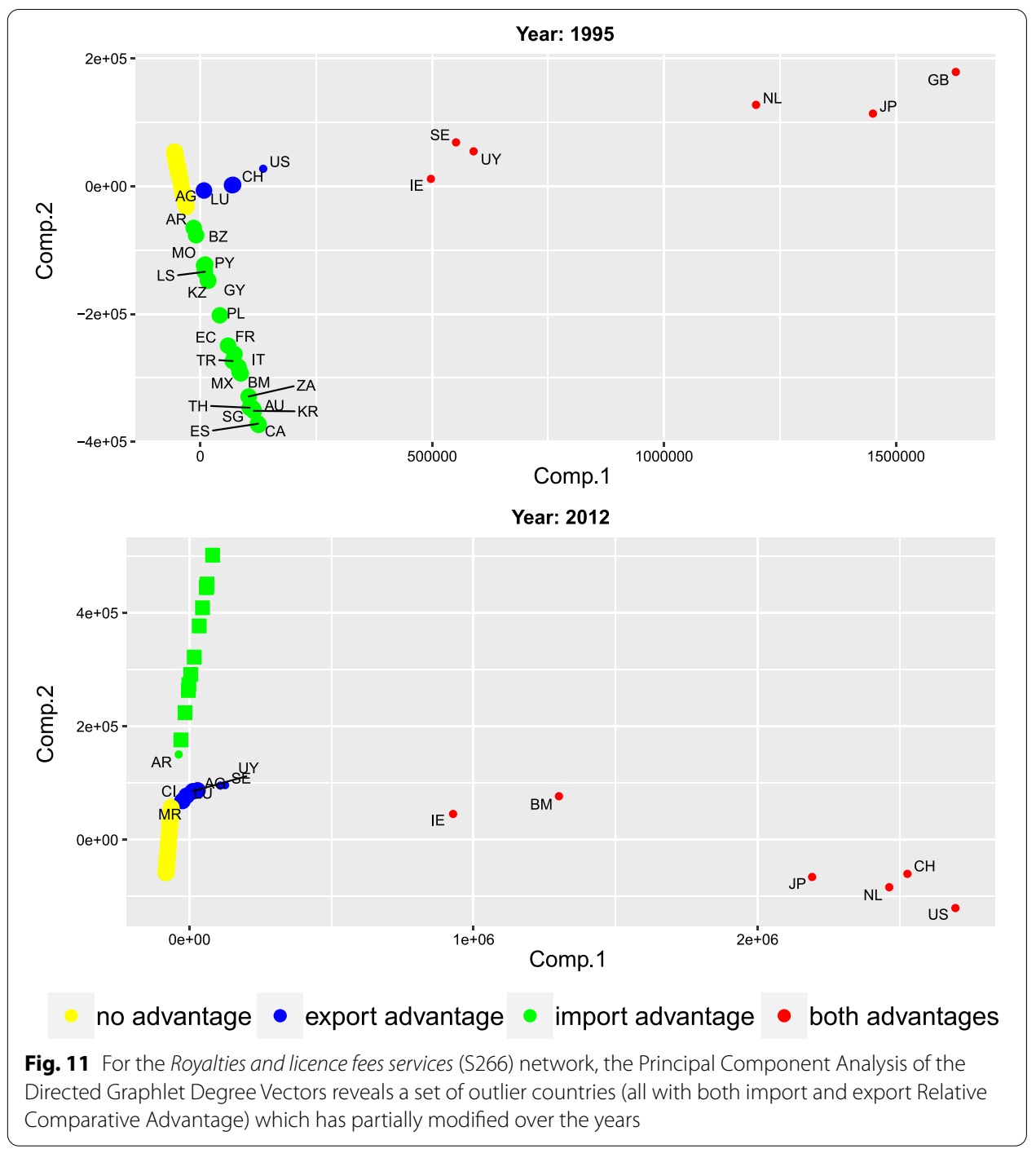

shows an increasing trend in all categories. An interesting result obtained by comparing the networks of different service categories through the Directed Graphlet Correlation Distance shows that two groups of traded services clearly emerge-Connection services on the one hand, and Business and Personal services on the other-each including services with similar topological characteristics.

The observed high network density brings with it a small unweighted centralization of the service networks, which contrasts with the high weighted centralization we find: while the large majority of countries in the world are connected through the exchange of services, a small group of countries is responsible for most of the flows. Connections within the service networks are unevenly distributed, especially for some service categories. Countries' positions in these networks are quite diversified, and central positions are mostly occupied by advanced countries. Differently than in the case of trade in goods, emerging and developing countries very rarely display 
a high centrality, regardless of the centrality measure used. It is worth noticing that some differences in countries positions emerge when comparing simpler centrality measures, such as out- and in-strength, to more complex network-dependent measures such as Pagerank or Hubness.

The centrality of a few advanced countries does not seem to depend (only) on their higher GDP, and consequently higher trade values, because the position occupied by countries in the service networks is often affected by more than their economic size. Interestingly, in the trade of many service categories, countries' role is revealed by the structure of their connections. This confirms the relevance of considering the topological structure of the network when analyzing countries importance in service trade.

Overall, the results of the analysis performed show that services are a key element of the globalization process, and we can expect that their role will keep increasing in the future. The network of trade in services is changing over time, like the position of the countries within it, and monitoring its evolution will be important to correctly understand the trends in global markets. At the same time, it will be crucial to monitor the co-evolution of the trade networks of goods and services, not only to highlight their similarities or differences, but most importantly to understand their increasing intertwining relationship.

\section{Appendix 1: Weighted centralization index}

In this appendix the definition and the computational properties of the weighted centralization index, discussed in Sect. Global network properties, are described. Its goal is to evaluate the centralization of a given network by quantifying how much it is similar to the most centralized type of graph, the star network. We use the vulnerability index defined by Piccardi and Tajoli (2018) and derived by the work of Dall'Asta et al. (2006), which measures how rapidly the aggregated network weight is lost when connectivity decreases because nodes are subsequently removed starting from those with largest out-strength.

Definition 1 (Vulnerability Profile) Let $G$ be a directed weighted graph, $S=\sum_{i j} w_{i j}$ its total strength, and, without loss of generality, assume that the $n$ nodes are numbered according to their out-strength in non increasing order, i.e. $s_{1}^{\text {out }} \geq s_{2}^{\text {out }} \geq \ldots \geq s_{n}^{\text {out }}$. We define the Vulnerability Profile as the sequence $1=v_{0} \geq v_{1} \geq \ldots \geq v_{n-1}=v_{n}=0$, such that

$$
v_{k}=\left\{\begin{array}{l}
1 \quad \text { if } k=0, \\
\frac{S_{k}}{S} \text { if } k=1,2, \ldots, n-1,
\end{array}\right.
$$

where $S_{k}$ is the total strength of the network after removing nodes $1,2, \ldots, k$ (removing a node implies deleting all its in- and out-edges). Moreover, the Vulnerability Curve is defined by interpolating the points $\left(k, v_{k}\right)_{k=0,1, \ldots, n}$ with a piecewise linear function connecting subsequent pairs. 
The expressions of the Vulnerability Profiles for the complete homogenous weighted graph and for the star graph can be explicitly computed.

Proposition 1 (Vulnerability profile of complete graphs) For a complete directed weighted graph of n nodes with homogenous weights, the vulnerability profile is the sequence

$$
v_{k}=\frac{(n-k)(n-k-1)}{n(n-1)}, k=0,1, \ldots, n .
$$

Proof

Since the weights are homogenous we assume, without loss of generality, that $w_{i j}=1 \forall i, j$, thus all nodes have the same out-strength $s_{i}^{\text {out }}=n-1, i=1,2, \ldots, n$. The total strength of the initial network is $S=L=$ number of links $=n(n-1)$. After removing nodes $1,2, \ldots, k$ of the sequence and all of their links, the resulting graph is a complete one composed by $n-k$ nodes only, with total strength $(n-k)(n-k-1)$, therefore

$$
v_{k}=\frac{S_{k}}{S}=\frac{(n-k)(n-k-1)}{n(n-1)} .
$$

Proposition 2 (Vulnerability profile of star graphs) For a directed star graph of $n$ nodes with homogenous weights and such that node $n$ is the central node, i.e. $w_{n i}=w_{\text {in }}=\bar{w}>0$, $i=1,2, \ldots, n-1$, and $w_{i j}=0, i, j=1,2, \ldots, n-1$, the vulnerability profile is the sequence

$$
v_{k}=\left\{\begin{array}{ll}
1 & \text { if } k=0 \\
0 & \text { otherwise }
\end{array} .\right.
$$

Proof

Assuming without loss of generality that $\bar{w}=1$, the out-strength of the nodes is $s_{i}^{\text {out }}=1$ for $i=1,2, \ldots, n-1$, and $s_{n}^{\text {out }}=n-1$. The first node to be removed, according to Definition 1 , is node $n$, and removing it the resulting network has no links, so that $S_{0}=S$ and $S_{k}=0$ for $k=1,2, \ldots, n$. Therefore $v_{0}=S_{0} / S=1$, and $v_{k}=0$ for $k=1,2, \ldots, n$.

The centralization index for a generic network is defined as the measure of the area under the associated Vulnerability Profile: this area will collocate between the two extremes associated to the complete graph and the star graph. To have a normalized index, assuming unitary values for star graphs and null values for complete graphs, we will normalize the area related to the network under study with respect to the area related to the complete graph.

Proposition 3 The area under the Vulnerability Curve of a complete directed graph of $n$ nodes with homogenous weights is given by 


$$
A_{\text {complete }}=\frac{2 n-1}{6} \text {. }
$$

Proof

As specified in Definition 1, the Vulnerability Curve is obtained by interpolating the profile with straight segments and thus the area is computed as a sum of trapezoidal areas with elements coming from the vulnerability profile derived in Proposition 1:

$$
\begin{aligned}
A_{\text {complete }} & =\sum_{k=1}^{n} \frac{v_{k-1}+v_{k}}{2}=\frac{1}{2} \sum_{k=1}^{n}\left[\frac{(n-k+1)(n-k)}{n(n-1)}+\frac{(n-k)(n-k-1)}{n(n-1)}\right] \\
& =\frac{1}{2} \frac{1}{n(n-1)} \sum_{k=1}^{n}(n-k)(n-k-1+n-k+1) \\
& =\frac{1}{n(n-1)} \sum_{k=1}^{n}(n-k)^{2}=\frac{1}{n(n-1)} \sum_{k=1}^{n-1} k^{2} \\
& =\frac{1}{n(n-1)} \frac{(2(n-1)+1)(n-1)(n-1+1)}{6}=\frac{2 n-1}{6}
\end{aligned}
$$

For star graphs, it is straightforward to verify that such area in given by $A_{\text {star }}=0.5$ since the Vulnerability Profile has only the first value which is non zero. Given these two extreme values, the Vulnerability Index can finally be defined in the following way.

Definition 2 (Vulnerability Index) Let $G$ be a directed weighted graph of $n$ nodes and let $\left\{v_{k}\right\}_{k=0,1, \ldots, n}$ be its Vulnerability Profile. We define the Vulnerability Index as

$$
V=1-\frac{\frac{1}{2} \sum_{k=1}^{n}\left(v_{k}+v_{k-1}\right)-A_{\text {star }}}{A_{\text {complete }}(n)-A_{\text {star }}}
$$

where $A_{\text {complete }}(n)=\frac{2 n-1}{6}$ and $A_{\text {star }}=0.5$.

With such definition, one can easily check that $V=0$ for complete graphs with homogenous weights and $V=1$ for star graphs as those considered in Proposition 2.

\section{Abbreviations}

BaTis: Balanced trade in services database; IMF: International monetary fund; OECD: Organization for economic cooperation and development; UN: United nations; WTO: World trade organization.

\section{Acknowledgements}

Not applicable.

Author contributions

LT, FA and CP conceived the research, conducted the experiments, wrote and reviewed the manuscript. All authors read and approved the final manuscript.

Funding

Not applicable 
Availability of data and materials

Trade in services data are publicly available at https://www.wto.org/english/tratop_e/serv_e/gatsqa_e.htm.

\section{Declarations}

Competing interests

The authors declare that they have no competing interests.

Received: 10 June 2021 Accepted: 5 August 2021

Published online: 06 September 2021

\section{References}

WTO: World Trade Report 2019. The Future of Services Trade. World Trade Organization, Geneva (2019)

UN, Eurostat, IMF, OECD, WTO: Manual on Statistics of International Trade in Services. United Nations, Geneva (2011)

Kimura F, Lee H-H (2006) The gravity equation in international trade in services. Rev World Econ 142:92-121. https://doi.org/ 10.1007/s10290-006-0058-8

Miroudot S, Sauvage J, Shepherd B (2013) Measuring the cost of international trade in services. World Trade Rev 12(4):719735. https://doi.org/10.1017/S1474745613000049

Francois J, Hoekman B (2010) Services trade and policy. J Econ Literat 48(3):642-692. https://doi.org/10.1257/jel.48.3.642

Freund C, Weinhold D (2002) The internet and international trade in services. Am Econ Rev 92(2):236-240. https://doi.org/10. $1257 / 000282802320189320$

WTO: The General Agreement on Trade in Services (GATS): objectives, coverage and disciplines (1995). https://www.wto.org/ english/tratop_e/serv_e/gatsqa e.htm

OECD-WTO: Balanced Trade in Services Dataset (2017). https://www.wto.org/english/res_e/statis_e/trade_datasets_e.htm Accessed April 2020

Fortanier F, Liberatore A, Maurer A, Pilgrim G, Thomson L (2017) The OECD-WTO balanced trade in services database .https:// www.wto.org/english/res_e/statis_e/trade_datasets_e.htm

De Lombaerde P, lapadre L, McCranie A, Tajoli L (2018) Using network analysis to study globalization, regionalization, and multi-polarity-Introduction to special section. Network Sci 6(4):494-516. https://doi.org/10.1017/nws.2018.25

Schiavo S, Reyes J, Fagiolo G (2010) International trade and financial integration: a weighted network analysis. Quantit Finance 10(4):389-399. https://doi.org/10.1080/14697680902882420

Piccardi C, Tajoli L (2018) Complexity, centralization and fragility in economic networks. PLoS ONE 13:0208265. https://doi.org/ 10.1371/journal.pone.0208265

Cingolani I, lapadre L, Tajoli L (2018) International production networks and the world trade structure. Int Econ 153:11-33. https://doi.org/10.1016/j.inteco.2017.10.002

Serrano MA, Boguna M, Vespignani A (2007) Patterns of dominant flows in the world trade web. J Econ Interact Coordin 2:111-124. https://doi.org/10.1007/s11403-007-0026-y

Borchert I, Mattoo A (2010) The crisis-resilience of services trade. Serv Ind J 30(13):2115-2136. https://doi.org/10.1080/02642 060903289944

Silva JMCS, Tenreyro S (2006) The log of gravity. Rev Econ Stat 88(4):641-658. https://doi.org/10.1162/rest.88.4.641

Dueñas M, Fagiolo G (2013) Modeling the international-trade network: a gravity approach. J Econ Interact Coordin 8(1):155178. https://doi.org/10.1007/s11403-013-0108-y

UN Statistics Division: Manual on Statistics of International Trade in Services 2010 (MSITS 2010) (2010). https:/unstats.un.org/ unsd/tradeserv/TFSITS/manual.htm

De Benedictis L, Nenci S, Santoni G, Tajoli L, Vicarelli C (2014) Network analysis of World Trade using the BACI-CEPII dataset. SSRN Electron J 14. https://doi.org/10.2139/ssrn.2374354

Dall'Asta L, Barrat A, Barthelemy M, Vespignani A (2006) Vulnerability of weighted networks. J Stat Mech Theory Exp. https:// doi.org/10.1088/1742-5468/2006/04/P04006

Tantardini M, leva F, Tajoli L, Piccardi C (2019) Comparing methods for comparing networks. Scientific Reports 9:17557. https://doi.org/10.1038/s41598-019-53708-y

Sarajlic A, Malod-Dognin N, Yaveroglu ON, Przulj N (2016) Graphlet-based characterization of directed networks. Scientific Reports 6:35098. https://doi.org/10.1038/srep35098

Balassa B (1965) Trade liberalisation and revealed comparative advantage. Manchester School 33:99-123. https://doi.org/10. 1111/j.1467-9957.1965.tb00050.x

Rousseeuw PJ (1987) Silhouettes: a graphical aid to the interpretation and validation of cluster analysis. J Comput Appl Math 20:53-65. https://doi.org/10.1016/0377-0427(87)90125-7

Brin S, Page L (1998) The anatomy of a large-scale hypertextual web search engine. Comput Networks ISDN Syst 30(1):107117. https://doi.org/10.1016/S0169-7552(98)00110-X

Kleinberg JM (1999) Authoritative sources in a hyperlinked environment. J ACM 46:604-632. https://doi.org/10.1 145/324133. 324140

Guimera R, Amaral L (2005) Cartography of complex networks: Modules and universal roles. J Stat Mech Theory Exp 02001. https://doi.org/10.1088/1742-5468/2005/02/P02001

Henderson K, Gallagher B, Eliassi-Rad T, Tong H, Basu S, Akoglu L, Koutra D, Faloutsos C, Li L (2012) Rolx: Structural role extraction and mining in large graphs. In: Proceedings of the 18th ACM SIGKDD international conference on knowledge discovery and data mining. KDD '12, pp. 1231-1239. ACM, New York, NY, USA . https://doi.org/10.1145/2339530.2339723 
Beguerisse-Diaz M, Garduno-Hernandez G, Vangelov B, Yaliraki SN, Barahona M (2014) Interest communities and flow roles in directed networks: the Twitter network of the UK riots. J R Soc Interface 11(101):20140940. https://doi.org/10.1098/rsif. 2014.0940

Grover A, Leskovec J (2016) Node2vec: Scalable feature learning for networks. In: Proceedings of the 22nd ACM SIGKDD international conference on knowledge discovery and data mining. KDD '16, pp. 855-864. ACM, New York, NY, USA . https:// doi.org/10.1145/2939672.2939754

Mechiche-Alami A, Piccardi C, Nicholas KA, Seaquist JW (2019) Transnational land acquisitions beyond the food and financial crises. Environ Res Lett 14(8):084021. https://doi.org/10.1088/1748-9326/ab2e4b

Johnson RA, Wichern DW (2008) Applied multivariate statistical analysis, 6th edn. Pearson, USA

\section{Publisher's Note}

Springer Nature remains neutral with regard to jurisdictional claims in published maps and institutional affiliations.

Submit your manuscript to a SpringerOpen ${ }^{0}$ journal and benefit from:

- Convenient online submission

- Rigorous peer review

- Open access: articles freely available online

- High visibility within the field

Retaining the copyright to your article

Submit your next manuscript at $\boldsymbol{\nabla}$ springeropen.com 